\title{
Competitive Balance and Consumer Demand in the English Football League
}

\author{
Misael Martinez ${ }^{1}$, Jonathan Willner ${ }^{2}$ \\ ${ }^{1}$ Student, Oklahoma City University, 2501 N. Blackwelder Ave. Oklahoma City, OK 73106-1493, USA \\ ${ }^{2}$ Professor of Economics, Oklahoma City University, 2501 N. Blackwelder Ave. Oklahoma City, OK 7106-1493, USA \\ Correspondence: Jonathan Willner, Professor of Economics, Oklahoma City University, 2501 N. Blackwelder Ave. \\ Oklahoma City, OK 7106-1493, USA.
}

Received: May 9, 2016

doi:10.11114/afa.v3i2.2411
Accepted: May 30, $2017 \quad$ Available online: June 7, 2017

URL: https://doi.org/10.11114/afa.v3i2.2411

\begin{abstract}
Competitive balance in sports leagues is often used to justify revenue sharing agreements. The justification is that competitive balance leads to higher attendance and higher attendance generates more revenues. By sharing revenue, small market teams can afford to pay for high quality talent, assuring more equal distribution of that talent. Unlike US professional leagues, English football operates under a system of relegation and promotion so that at the end of each season the worst performing teams are "relegated" and the top performing teams in the next level down are "promoted". This may serve as an alternative to revenue sharing to maintain competitive balance.

Using data from the top English football league (currently the Premiership) from 1888-89 through the 2014-15 season we calculate multiple measures of league competitive balance for each year using both 3-1-0 and 2-1-0 point systems. We then use these measures with available macroeconomic control variables to examine the relationship between competitive balance and match attendance.

We find that, counter to related work in US sports leagues, competitive balance in English football is negatively associated with attendance. This is particularly true in the case of the Premiership era, wherein only five teams have won the championship and in the past 10 seasons, the top 4 places of the championship has been dominated by 7 clubs, yet attendance has steadily increased. This result raises questions about the utility of revenue sharing in increasing attendance in English football.
\end{abstract}

Keywords: competitive balance, football, England

\section{Introduction}

Since the early days, professional sports leagues have believed in the importance of competitive balance in maintaining league viability. Competitive balance implies uncertainty of outcome, whether by game or by final league standings who's going to be the champion? The basis for the belief is that fans prefer a close contest to a foregone conclusion. Consequently, leagues try to encourage competitive balance in the belief that it will maintain or increase fan attendance. Whether teams and leagues are utility maximizing or profit maximizing, fan interest and attendance are crucial to financial viability.

In U.S. professional leagues, revenue sharing has become a common mechanism to maintain competitive balance. Revenue sharing transfers some ability to buy talent from high revenue teams to lower revenue teams. An alternative mechanism, common in European football, is the promotion/relegation approach. With this approach, poor performing teams are removed from the top division each year and replaced by the best performing teams in the next lower division. With the advent of the Premiership in English football, both mechanisms for achieving competitive balance have been implemented in the top division. The promotion and relegation approach is believed to have a significant effect on consumer demand because it adds uncertainty to the league (Siegfried \& Sanderson (2003)). If successful, the resulting improvements should increase match attendance.

In the Premiership, promotion with revenue sharing can be quite a boon for the promoted team. Gross receipts grow dramatically. When Cardiff, Hull and Crystal Palace were promoted to the Premiership at the end of the 2012-13 season they had gross revenues of $\$ 27 \mathrm{~m}$., $\$ 26 \mathrm{~m}$. and $\$ 22 \mathrm{~m}$. for the year. In their first year in the Premiership, 2013-14, they 
each saw an increase of over $\$ 100 \mathrm{~m}$. in receipts. Much of this additional revenue was put into wages; presumably to purchase the contracts of better players. This approach of improved talent and new teams may increase attendance at games in the top league. The newcomers are an uncertain commodity. Relegation, despite parachute payments, will likely have the same, but negative, effects, though cushioned. Whether this talent purchase is win maximizing or profit maximizing over the long-run is not obvious in the first year after promotion.

Competitive balance can refer to the season-long race between teams for a league championship, or the closeness and uncertainty of outcome of given a contest, game, or match (Rascher \& and Solmes (2007)). Contests/games with a higher level of outcome uncertainty are more entertaining, leading to a larger consumer demand for game tickets and broadcasting rights. Previous research indicates a significant positive relationship between competitive balance and game attendance. If competitive balance increases and all teams have a more equal opportunity of winning, then the uncertainty of outcome will increase and game attendance and general consumer demand will increase as well.

The long history of English football has had several disruptions of consequence that also marked large changes in the society. The first disruption was World War I. The league did not operate from 1914 through 1918 . The end of the war also revealed the "Lost Generation" as over 700,000 young men died and well over a million were injured in combat. Consequently, both players and the potential fan base were drastically reduced. For the purposes of this paper, seasons before 1914 are referred to as "PreWWI". The next major disruption was World War II. The period between Great Wars we call "Interwar". After World War II, as with after World War I, (PostWWTwo) England experienced significant change; the economy was ravaged, another generation of young men was lost and injured and the Empire unraveled. After the 1991 season the Premier League was formed which radically altered how English Football was managed. We refer to this last era as "Premiership". We refer to the period 1946-1991 as "Post2NoPre".

In the 113 seasons contested between 1888 and 2014, a total of 66 different teams have played in the top English football division. Table 1 shows how top finishes have been distributed over the period. Only 22 (33\%) teams have won a championship, but 40 (61\%) have managed a top 4 finish. Throughout the different eras of English football, broken up by wars, the share of teams that have won the top position has varied from 24 to $29 \%$ until the Premiership. During the 23 years of the Premiership 46 teams have contested but only 5, 11\% have won the championship and only $13(28 \%)$ have managed a top 4 finish. Contrast this with US professional baseball where, since 1903, 25 franchises of 30 have won the World Series. Measured in terms of top finishes, English football appears to have much lower competitive balance and the Premiership, even lower.

Table 1. English Football Top Finishes

\begin{tabular}{llllll}
\hline & All Years & PreWWI & InterWar & Post2NoPre & Premiership \\
\hline Teams & 66 & 35 & 38 & 52 & 46 \\
Titles & 113 & 26 & 19 & 45 & 23 \\
Teams with Titles & 22 & 10 & 9 & 15 & 5 \\
Share with Titles & $33 \%$ & $29 \%$ & $24 \%$ & $29 \%$ & $11 \%$ \\
Teams with Top 4 Finishes & 40 & 20 & 23 & 31 & 13 \\
Share with Top 4 Finishes & $61 \%$ & $57 \%$ & $61 \%$ & $60 \%$ & $28 \%$
\end{tabular}

Despite the apparently low degree of competitive balance, as measured by championship wins and top 4 positions, the Premier league has the highest revenue and spectator attendance of any football league in the world. Since 2013, it has generated about $£ 1.76$ or $\$ 2.75$ billion per year in broadcasting rights. Therefore, the question of why a low competitive balance league can be one of the most profitable and most attended leagues in the world arises. Perhaps previous findings on competitive balance do not apply to the Premier League.

This paper tests the competitive balance hypothesis in The English Football League First Division (known as The English Premier League since 1992) from the 1888-89 season through the 2014-15 season. Competitive balance is measured using three competing approaches and two methods of accounting. We use a total of six (6) measures of competitive balance: 3 types (adjusted Gini coefficient, HHI* and Idealized Standard Deviation) and two methods of counting points (3-1-0 and 1-1-0).

\section{Literature}

In The Peculiar Economics of Professional Sports, Walter C. Neale (Walter C. Neale, 1964) provided an extended explanation of why, in sporting leagues, the reduction of competition leads to a decrease of profitability, rather than an increase. Neale's logic is that sporting firms "produce an individual product from the separate processes of two or more firms." Therefore, the game itself is a joint product. This product is complex and includes not only the game but also the sporting event as a whole and all utilities created by the sporting firm such as seats, and stadium conditions. The 
consumers' acceptance of the product depends on the inputs invested, and the consumers' willingness to consume the product to achieve a stream of utility. A single team cannot produce any of these "streams of utility" alone, it must have the cooperation of several more teams or business firms to produce the product, the game. This is then the entry for the role of competitive balance as a potentially necessary aspect of a sports league. If the consumers' utility is increased by watching a close match as opposed to a blow-out, all teams rationally want close matches.

Measuring competitive balance in a sports league has a long history of competing methods. Competitive balance should be seen as distinct from uncertainty of outcome as the former examines league wide conditions and the latter takes a game-by-game approach. Both approaches are often examined in light of fan support, whether attendance at games or in terms of viewership of broadcasts.

Uncertainty of outcome literature generally uses measures of current standings and winning percentages of the teams involved in each contest. Tainsky \& Winfree, (Tainsky \& Winfree, 2010), Rascher (Rascher, 1999) and Knowles, Sherony and Haupert (Knowles, Sherony and Haupert, 1992) find that greater uncertainty of outcome is associated with higher game attendance in Major League Baseball (MLB). Surdam, (Surdam, 2009), finds this result may be dependent upon individual team fan base preferences. In the National Basketball Association, Rascher and Solmes (Rascher and Solmes, 2007) find similar results to those of MLB. Paul and Weinbach (Paul and Weinbach, 2007) find that uncertainty of outcome is associated with higher viewership for National Football League Monday night broadcast. In football, Peel and Thomas (Peel and Thomas, 1988) find a positive association between uncertainty of outcome and attendance in Scottish League football. Jennett (Jennett, 1984) finds the evidence of this relationship to be weak. In English football leagues, across 4 divisions, Peel and Thomas (Peel and Thomas, 1992) find a positive association between outcome uncertainty and attendance. This literature supports the notion that fans like close contests. Most of the above literature also finds a bit of home bias. Home fans like a close game, but with a slightly higher than 50:50 chance of the home team winning.

The empirical literature on competitive balance and attendance finds either a positive or no relationship between the two. Schmidt and Berri (Schmidt and Berri, 2001) examining MLB and Hogan, P. Massey and S. Massey (Hogan, P. Massey and S. Massey, 2013) in European Rugby Union find a positive relationship. Scelles, Durand, Bonnal, Goyeau and Andreff (Scelles, Durand, Bonnal, Goyeau and Andreff, 2013), in French Football Ligue1 and Szymanski (Szymanski, 2001) in English football, across 4 leagues from 1978 through 1998, finds no relationship. Brandes and Franck (Brandes and Franck, 2007), looking across multiple European football leagues, find no consistent relationship.

These findings are unsurprising in light of the literature on profit- versus win-maximizing owner and league behavior. Peeters (Peeters, 2015), Vrooman (Vrooman, 2009) and Palomino and Tigotti (Palomino and Tigotti, 2000) make it clear that it is not always the objective of owners to maximize profits, some may be more interested in wins. Consequentely, efforts to achieve competitive balance may have different results across leagues, teams and time. It may further be the case that fans are similarly different in their approach to a given sport or team.

Hall, Szymanski and Zimbalist (Hall, Szymanski and Zimbalist, 2002) provide evidence that revenue sharing may improve competitive balance through the expected mechansim for buying talent in the NBA. Dobson and Goddard (Dobson and Goddard, 2004) find that in the absence of revenue sharing, in a profit maximizing league, competitive balance declines.

One possible alternative to competitive balance and outcome uncertain explanations for attendance is the role of the super star. Hausman and Leonard (Hausman and Leonard, 1997) and Berri and Schmidt (Berri and Schmidt, 2006) both document attendence changes associated with superstars. It may be the case that fans like a close contest, but one that features the exceptional talent, or that they simply prefer to watch the exceptional talent. In international football this may translate into fans having a preference for watching national team members, whether from their own country or elite players from other countries.

A central issue of the competitive balance literature is how best to measure it. The Gini coefficient as used by Schmidt and Berri (Schmidt and Berri, 2001) is one such approach. In this case, the Gini Coefficient measures the distribution winning percentages. Following Lambert (Lambert, 1993) the Gini Coefficient is calculated as:

$$
\text { Gini }_{t}=\left(1+N_{t}\right)-\frac{2}{N_{t}^{2} \mu_{X_{t}}} *\left(X_{N, t}+2 * X_{N-1, t}+3 * X_{N-2, t}+\cdots+N * X_{l, t}\right)
$$

Where $\mathrm{X}_{\mathrm{N}, \mathrm{t}}$ is the share of possible points received by the $\mathrm{N}^{\text {th }}$ ranked team, $\mathrm{N}=1 \rightarrow 1$ in year $\mathrm{t}$ and $N_{T \times \mathrm{t}}^{2}$ is the mean of $\mathrm{X}_{\mathrm{N}, \mathrm{t}}$ in the year.

The Gini Coefficient, when measuring income distribution, allows for one individual to have approximately $100 \%$ of income while everyone else has 0 . In football this cannot occur - a club may win all its games, but cannot win a game played between two other teams. Consequently, Utt and Fort (Utt and Fort, 2002) proposed a modification based on 
developing as unequal a distribution of wins and losses as is possible in a league. Mizak, Stari and Rossi (Mizak, Stari and Rossi, 2005) provide a simple formulation for this calculation. First the Gini Coefficient is calculated as in Schmidt and Berri (Schmidt and Berri, 2001) then a similar calculation is done but with results based on the first place team going undefeated, the second place team losing only to the first place team, etc. Call this second Gini, Gini $\mathrm{PI}_{\text {. The }}$ modified Gini, Gini $_{\text {Adj. }}$ is then:

$$
\operatorname{Gini}_{A d j}=\frac{\operatorname{Gini}_{t}}{\operatorname{Gini}_{P I}}
$$

An alternative measure of competitive balance from the industrial organization literature is the Herfindahl-Hirschman Index (HHI). The HHI, in the case of football, is based on share of league total points: The general HHI was calculated as (omitting the standard multiplier of 10,000):

$$
\sum_{N=1}^{l}\left(\frac{\text { Points }_{N}}{\sum_{N=1}^{l} \text { Points }_{l}}\right)^{2}
$$

Owen, Ryan and Weatherston (Owen, Ryan and Weatherston, 2007) point out that this measure is subject to measurement error in sports leagues due to upper and lower boundaries of the calculation. To account for this, they suggest a modified HHI, HHI*. HHI* which accounts for the limits of share of points as no team can achieve $100 \%$ of points and the maximum share is determined by the number of clubs.

$$
H H I^{*}=\frac{3 * \text { Clubs } *(\text { Clubs }-1)}{\text { Clubs } *(\text { Clubs }+1)} *(H H I-1)
$$

Another commonly used measure of league wide competitive balance is the "Idealized Standard Deviation" (ISD) approach. The ISD measure is the ratio of the standard deviation of wins when each team is equally likely to win each match to that of the actual distribution of wins.

$$
\frac{\mu_{X_{t}} /}{\frac{\operatorname{Games}_{N=1}\left(X_{i}-\bar{x}\right)^{2}}{l}}
$$

where $\cdot \mathrm{Xt}$ is the average number of points a club would earn in the ideal equal league, $\mathrm{Xi}$ is the number of points the $i$ th club earned and $l$ is the number of clubs. "Games" is the number of matches played by each team.

Examining changes in competitive balance across time gives an indication of how the league changes with different policies and regulations. Cain and Haddock (Cain and Haddock, 2006) examine movements around parity in MLB and in English football's top two divisions. They note that MLB is moving towards parity. However, English football is moving away from parity, having moved towards soon after WWII. Lee and Fort (Lee and Fort, 2012) go some way in explaining the "U-shaped nature" of competitive balance measures in the English top division by identifying breaks in the data consistent with World Wars and the introduction of the Premier League. Lee and Fort (Lee and Fort, 2005) identify structural breaks in competitive balance measures in MLB.

Whether or not competitive balance is associated with attendance, many professional sports leagues institute a revenue sharing policy to achieve it. Cavagnac (Cavagnac, 2009) develops a model which indicates revenue sharing will increase competitive balance. Kesenne (Kesenne, 2006) develops models that indicate the effect of revenue sharing on competitive balance depends on the objective - wins or profits. Szymanski and Kesenne (Szymanski and Kesenne, 2004), Grossmann, Dietl and Lang (Grossmann, Dietl and Lang, 2010) and Runkel (Runkel, 2011) all develop models where revenue sharing does not increase competitive balance.

\section{Data}

The data was compiled from multiple sources. Team performance was downloaded from the Rec.Sport.Soccer Statistics Foundation (http://www.rsssf.com/engpaul/fla/league.html) website. Attendance data was acquired from The European Football Statistics (www.european-football-statistics.co.uk) website.

Macroeconomic control variables that are consistent across the time frame are difficult to obtain. Real Gross Domestic Product (rGDP) used was obtained from "The UK recession in context - what do three centuries of data tell us?"- Data Annex: (http://www.bankofengland.co.uk/publications/Documents/quarterlybulletin/threecenturiesofdata.xls). This provides annual rGDP through 2009. The Conference Board provides access to marco-economic data (http://www.conference-board.org/data/economydatabase/) commencing in 1950 and running through 2015, including population. For pre-1950 population the Maddison Project (http://www.ggdc.net/maddison/maddison-project/home.htm) dataset was accessed. No site was found that reliably reported recession periods across the time frame used. The macroeconomic data was used to develop two series of variables: "long" from 1888 through 2009 and "mod" for 1950 
through 2014. Growth rates in rGDP, per capita rGDP and the population were calculated.

The football season starts in August and ends the following May. To account for the inconsistency between season and macroeconomic reporting periods the mean values for the season were created. The mean values were calculated as $\mathrm{rGDP}_{\mathrm{t}}=\left(\mathrm{rGDP}_{\mathrm{t}}+\mathrm{rGDP}_{\mathrm{t}+1}\right) / 2$, etc. where $\mathrm{t}$ is the year of the start of a season. A simple approach was then taken to calculate recessionary periods in a season. If mean $\mathrm{rGDP}_{\mathrm{t}}<$ mean $\mathrm{rGDP}_{\mathrm{t}-1}$ a recessionary period was indicated. These closely match available series for recessions that are dated by year (start of the season) and, where available, by quarter ( 2 quarters of official recession in a season indicate a recession during the season).

England's long history with football was been interrupted multiple times during the $20^{\text {th }}$ century. The Pre-World War I (PreWWOne) period was taken as 1888 through 1913. The top league did not operate during the war years, leading to breaks in measured attendance and league play. Because of the dislocation associated with returning to a normal economic and social footing we removed 1919 and 1946 observations from our data. We called the period between wars, 1920-1938 "Interwar". After World War Two there were two quite different experiences. In 1992 the Premiership began, leaving two periods: from the 1940 season through 1991, "Post2NoPre" and the "Premiership" era from 1992. Figure 1 shows season total attendance for the league.

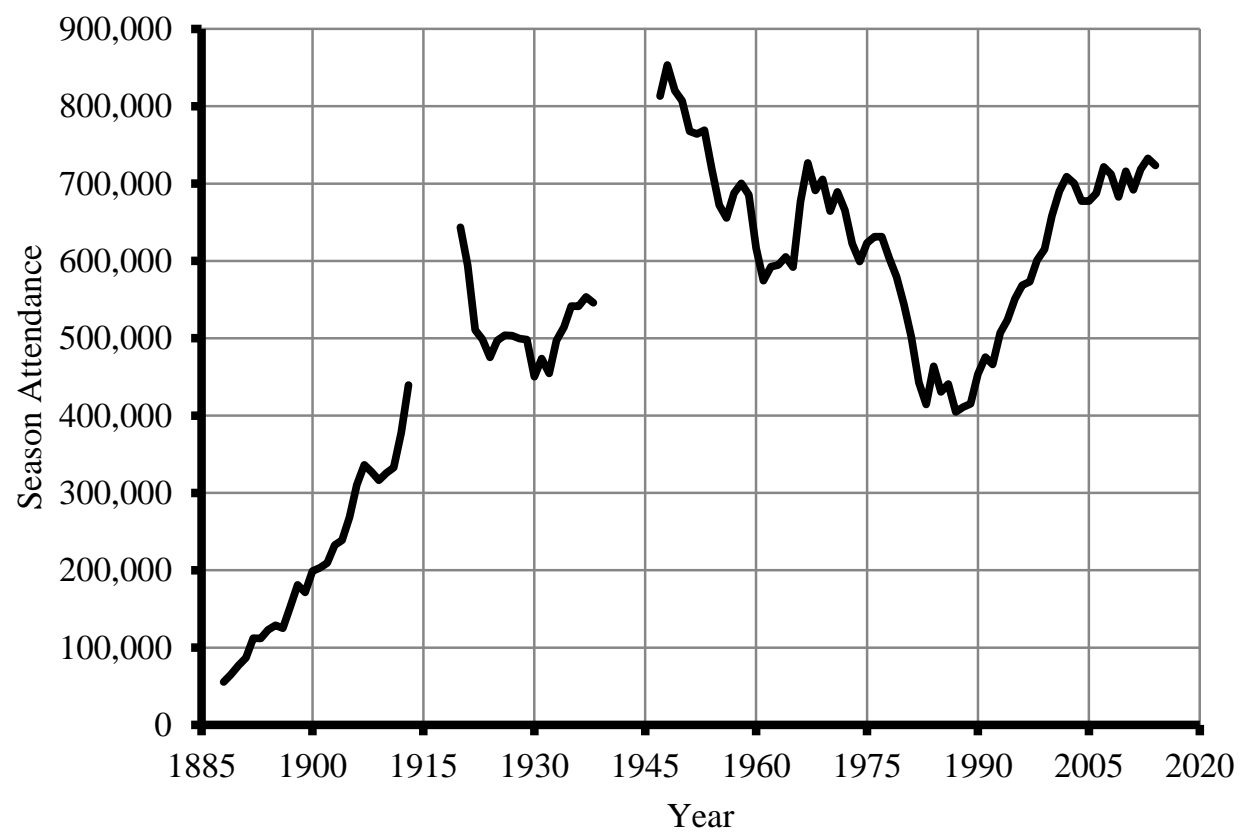

-AttLeaSea

Figure 1. Season Attendance (Sum of team's)

Attendance rose steadily up to WWI then experienced a precipitous drop in the Interwar period. This may be caused by war recovery and by the loss of a generation of young male fans. Attendance began to recover around 1928 with an expected dip at the advent of the Great Depression, then continued growth. Both economic growth and demographics may explain this as children born in the Interwar period begin to replace their deceased fathers in the stands. After WWII, as after WWI, attendance was higher than before the war. Mimicking post-WWI behavior, attendance soon declined. After a slight recovery in the 1960s, attendance again declined. Some of this decline may be a result of the hooliganism that infected English football (see Jewell, Simmons and Szymanski (Jewell, Simmons and Szymanski, 2014)). Attendance then started to increase with the beginning of the Premiership. Given the long stretch of time being considered much may have changed in terms of capacity of stadiums, etc. Capacity of each team's stadium would be useful. Unfortunately, there are two data issues that present themselves. The first is that during much of the time under consideration stadiums featured a "terrace" seating approach making the actual capacity of any stadium questionable. The second is that no reliable source exists for seating capacities at all stadia being considered.

Calculating competitive balance in a league with the possibility of tied contests created a complication in that a points system is required as opposed to a simple binary for win/loss. Until relatively recently, points were awarded 2 for a win, 1 for a draw and 0 for a loss (2-1-0). Currently, points are awarded 3 for a win, 1 for a draw and 0 for a loss (3-1-0). Point totals for each team in each season, using both the 2-1-0 and 3-1-0 point allocation methods, were calculated. 
Multiple measures of competitive balance exist, as discussed above. We calculated the three discussed above (Gini ${ }_{\text {Adj. }}$, Idealized Standard Deviation (ISD) and $\mathrm{HHI}^{*}$ ) using both the 3-1-0 and 2-1-0 points systems.

Figure 2 shows the time path of all three measures using the 2-1-0 points system. The 3-1-0 points system follows similar paths. There is considerable seasonal volatility in each of the 3 types used and each follows much the same path.

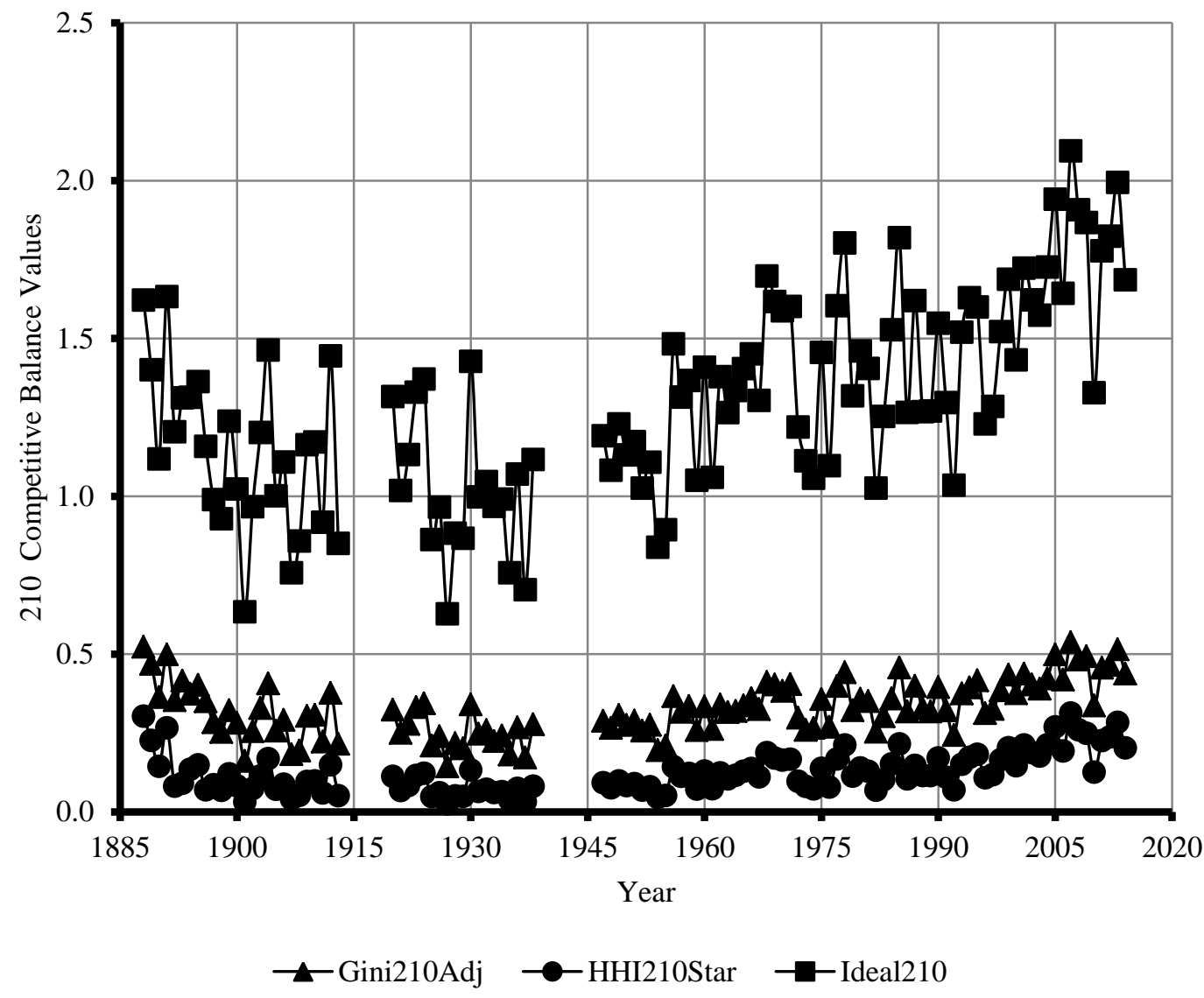

Figure 2. 2-1-0 Competitive Balance Measures

All competitive balance measures are highly correlated. Table 2 shows correlation coefficients for the levels of measured competitive balance. Though calculated differently, the correlations suggest they are measuring much the same phenomenon.

Table 2. Competitive Balance Measures Correlations

\begin{tabular}{lcccccc}
\hline & Gini210Adj & Gini310Adj & HHI210Star & HHI310Star & Ideal210 & Ideal310 \\
\hline Gini210Adj & 1 & & & & & \\
Gini310Adj & 0.994 & 1 & & & & \\
HHI210Star & 0.961 & 0.956 & 1 & & & \\
HHI310Star & 0.953 & 0.960 & 0.993 & 1 & & \\
Ideal210 & 0.956 & 0.962 & 0.942 & 0.947 & 1 & \\
Ideal310 & 0.942 & 0.958 & 0.930 & 0.947 & 0.994 & 1 \\
\hline
\end{tabular}


Table 3. Data Definitions and Summary Statistics

\begin{tabular}{|c|c|c|c|c|}
\hline Variable & Definition & Mean & Std. Dev. & Obs. \\
\hline AttLeaSea $_{t}$ & Sum of team's total attendance per season in year t. & 513,335 & 198,395 & 113 \\
\hline AttTeamGm & Individual team's average game attendance in year t. & & & \\
\hline Gini210Adj $\mathrm{j}_{\mathrm{t}}$ & $\begin{array}{l}\text { Gini Coefficient, } 2-1-0 \text { point allocation system in year t. } \\
\text { (Adjusted for team sports) }\end{array}$ & 0.330 & 0.086 & 113 \\
\hline $\operatorname{Gini} 10 \mathrm{Adj}_{\mathrm{t}}$ & $\begin{array}{l}\text { Gini Coefficient, } 3-1-0 \text { point allocation system in year t. } \\
\text { (Adjusted for team sports) }\end{array}$ & 0.363 & 0.096 & 113 \\
\hline HHI210Star & $\begin{array}{l}\text { 4-firm concentration ratio, 2-1-0 point allocation in year } t \text {. } \\
\text { (Adjusted for team sports.) }\end{array}$ & 0.124 & 0.063 & 113 \\
\hline HHI310Star ${ }_{t}$ & $\begin{array}{l}\text { 4-firm concentration ratio, 3-1-0 point allocation in year t. } \\
\text { (Adjusted for team sports.) }\end{array}$ & 0.150 & 0.077 & 113 \\
\hline Ideal210 & $\begin{array}{l}\text { Idealized Standard Deviation Competitive Balance, 2-1-0 point } \\
\text { allocation in year } t \text {. }\end{array}$ & 1.295 & 0.313 & 113 \\
\hline Ideal $310_{\mathrm{t}}$ & $\begin{array}{l}\text { Idealized Standard Deviation Competitive Balance, } 3-1-0 \text { point } \\
\text { allocation in year t. }\end{array}$ & 1.425 & 0.349 & 113 \\
\hline G210ShareP & $\begin{array}{l}\text { Individual team's share of season total points, } 2-1-0 \text { point } \\
\text { allocation in year } t \text {. }\end{array}$ & - & - & - \\
\hline G210ShareP & $\begin{array}{l}\text { Individual team's share of season total points, 3-1-0 point } \\
\text { allocation in year } t \text {. }\end{array}$ & - & - & - \\
\hline PlayedLeague $_{t}$ & Number of games per team in year $\mathrm{t}$. & 39.04 & 4.528 & 113 \\
\hline Played & Number of matches played by each club (?) in year $t$ & & & \\
\hline Interwar & Binary: 1 for years $1919-1939,0$ otherwise & 0.168 & 0.376 & 113 \\
\hline Post2NoPre & $\begin{array}{l}\text { Binary: } 1 \text { for years greater than } 1945 \text { and less than 1992, } 0 \\
\text { otherwise }\end{array}$ & 0.398 & 0.492 & 113 \\
\hline Premiership & Binary: 1 for years greater than 1991,0 otherwise & 0.204 & 0.404 & 113 \\
\hline RecessLongMean $_{\mathrm{t}}$ & $\begin{array}{l}\text { Binary: } 1 \text { for seasons with a recession, } 0 \text { otherwise, using } \\
\text { Maddison data }\end{array}$ & 0.142 & 0.350 & 113 \\
\hline GRrGDPPerCapLongMean & \multirow{2}{*}{\multicolumn{4}{|c|}{$\begin{array}{l}\text { Grow Rate of real Per Capita GDP using Maddison data } \\
\text { Prefix indicating change from year to year. For example, Dif AttLeaSea } t=A_{t} t L_{e a S e a}-\text { AttLeaSea }_{t-1}\end{array}$}} \\
\hline Dif___ & & & & \\
\hline
\end{tabular}

\section{Analysis}

The analysis proceeds in two steps. First we examine season attendance for the league and competitive balance measures. This is followed by a pooled approach to team game attendance averages and competitive balance. Our main variables of interest, competitive balance and attendance, were found to be non-stationary but trend-free using both the Augmented Dickey-Fuller and the Phillips-Perron methods. In both cases the $1^{\text {st }}$ differences were found to be stationary. We use the lagged value of "DifCompBalance ${ }_{t-1}$ " as changes in competitive balance in the league can only be observed in the past. Further, both Akaike Information Criterion and Schwarz Information Criterion indicate one lag is appropriate.

Using OLS, we estimated:

$$
\text { DifAttLeaSea }_{t}=\alpha+\beta * \text { DifCompBalance } \text { Li-1 }+\sum \gamma_{i} * X_{t}+\varepsilon_{t}
$$

where the $X_{t}$ are control variables for era and macroeconomic conditions.

Numerous models with different macroeconomic control variables were examined. Only RecessLongMean was found to be significant. Consequently, only regressions with RecessLongMean are reported. Tests for indicate some limited evidence of heteroscedasticity. To account for this, we used White's heteroscedasticity consistent standard errors. Table 4 provides initial results. 
Table 4. DifAttLeaSea

\begin{tabular}{lcccccc}
\hline \multicolumn{1}{c}{ Variable } & Model 1 & Model 2 & Model 3 & Model 4 & Model 5 & Model 6 \\
\hline $\mathrm{C}$ & $-832,936$ & $-853,407$ & $-843,350$ & $-860,446$ & $-870,845$ & $-887,744$ \\
Year & 450.4 & 460.4 & 459 & 467 & 471 & 479 \\
RecessLongMean & $-10,224$ & $-10,340$ & $-10,867$ & $-10,987$ & $-10,541$ & $-10,682$ \\
InterWar & $-29,907^{* *}$ & $-30,312^{* *}$ & $-29,107^{* *}$ & $-29,534 * *$ & $-29,810^{* *}$ & $-30,107^{* *}$ \\
Post2NoPre & $-54,351^{* *}$ & $-55,290^{* *}$ & $-53,739^{* *}$ & $-54,590^{* *}$ & $-55,119^{* *}$ & $-55,886^{* *}$ \\
Premiership & $-42,327$ & $-43,446$ & $-42,993$ & $-43,902$ & $-44,161$ & $-45,047$ \\
PlayedLeague & -170 & -129 & -353 & -300 & -198 & -167 \\
DifGini210Adj(-1) & $93,558 \dagger$ & - & - & - & - & - \\
DifGini310Adj(-1) & - & $84,717 \dagger$ & - & - & - & - \\
DifHHI210Star(-1) & - & - & $122,471 \dagger$ & - & - & - \\
DifHHI310Star(-1) & - & - & - & $103,121^{* *}$ & - & - \\
DifIdeal210(-1) & - & - & - & - & $24,680 \dagger$ & - \\
DifIdeal310(-1) & - & - & - & - & - & $22,447 * *$ \\
\hline adj. $\mathrm{R}^{2}=$ & 0.165 & 0.161 & 0.157 & 0.138 & 0.162 & 0.158 \\
$\mathrm{~N}=$ & 107 & 107 & 107 & 101 & 107 & 107 \\
\hline
\end{tabular}

Some clarification of possible coefficient estimate signs may be useful. If a competitive balance measure increases, competitive balance has declined. The prevailing theory is that an increase (decrease) in competitive balance should be associated with high (lower) attendance. Consequently, support for the theory would be indicated by a negative coefficient estimate: a higher competitive balance measure means lower competitive balance and so lower attendance. A positive coefficient would be the opposite of prevailing theory and some evidence.

The results provide for an interesting role for competitive balance. All measures of competitive balance are significant and positive. This suggests that a decrease in league competitive balance in the previous year is associated with increases in attendance this year; counter to much of the literature.

Both the Interwar and Post2NoPre coefficients were negative and significant, indicating a general decline of attendance at football matches after both World War I and World War II, relative to changes in the Pre-World War I period. The Premiership control was not significant. The remaining macroeconomic control variable was never significant. Its inclusion, as opposed to other controls, is a consequence of the second stage of the analysis.

With the system of promotion and relegation each season has different clubs and, consequently, a different sized fan base and stadium. In an effort to capture these changes we adopted a pooled approach with fixed effects for clubs. In this case we used differences in the average game attendance for each club in each year. We ran regressions of the form:

$$
\text { Dif AttTeamGM }_{t_{?}}=\alpha+\beta * \text { DifCompBalance } t_{-1}+\delta * \text { DifG\#10ShareP }_{t_{-}} ?+\sum \gamma_{i} * X_{t}+\varepsilon_{t}
$$

where indicates an individual club and "\#” is either 2 or 3 depending on how points were allocated for match outcomes. With the pooled approach it was possible to include a variable for team performance as well as league competitive balance. We included the year-to-year change in share of points a club received. If a club shows improvement in a year and moves up the league tables during that year it should attract larger crowds. Given the evidence of heteroscedasticity found we adopted White's robust standard errors. Table 5 clearly indicates that all competitive balance measures are largely interchangeable. In the interest of space constraints we use only Gini210Adj. and Ideal310. We match the team point share measure to the 2-1-0 and 3-1-0 approach of the competitive balance in each regression. Several different macroeconomic variables were used as robustness checks. An additional robustness check was the use of random period effects. Table 5 shows these regression results. 
Table 5. DifAttTeamGm_?

\begin{tabular}{|c|c|c|c|c|c|c|c|c|c|c|c|c|}
\hline Variable & Model 1 & Model 2 & Model 3 & Model 4 & Model 5 & Model 6 & Model 7 & Model 8 & Model 9 & Model 10 & Model 11 & Model 12 \\
\hline$\overline{\mathrm{C}}$ & -0.2981 & 119 & $-1,101$ & -320.9 & $5,161 \dagger$ & $-32,536^{*}$ & $-32,899 *$ & $-37,622 * *$ & $3,579 * *$ & $-35,334 *$ & $-41,048 * *$ & $3,458 * *$ \\
\hline Year & 3.173 & 3.121 & 3.757 & 3.415 & & $18.71^{*}$ & $19.2 *$ & $21.88 * *$ & - & $20.45^{* *}$ & $23.61 * *$ & $-549.3 * *$ \\
\hline RecessLongMean & $-566.5 \dagger$ & - & - & - & $-546.3^{*}$ & $-759.8 \dagger$ & $-688 \dagger$ & - & $-535.2 * *$ & $-708.7 \dagger$ & - & - \\
\hline RecessLong & - & -279.9 & - & - & - & - & - & - & - & - & - & - \\
\hline GRGDPLongMean & - & - & $8,006^{*}$ & - & - & - & - & - & - & - & $7,703^{*}$ & - \\
\hline GRrGDPPerCapLongMean & - & - & - & $7,797 *$ & - & - & - & $7,431^{*}$ & - & - & - & - \\
\hline Played_? & $-164.5 \dagger$ & $-165.2 \dagger$ & $-171.4 \dagger$ & $-173.2 \dagger$ & $-138.1 \dagger$ & $-74.09 *$ & $-83.48 * *$ & $-99.39 * *$ & -85.12 & $-82.78 * *$ & $-98.19 * *$ & -82.63 \\
\hline InterWar & - & - & - & - & - & $-742.1 *$ & $-835.2 * *$ & $-852 * *$ & -254.3 & $-841.7 * *$ & $-848.7 * *$ & -234.9 \\
\hline Post2NoPre & - & - & - & - & - & $-2,269 \dagger$ & $-2,314 \dagger$ & $-2,403 \dagger$ & $-865.1^{*}$ & $-2,374 \dagger$ & $-2,460 \dagger$ & $-851.6 *$ \\
\hline Premiership & - & - & - & & - & $-1,622$ & $-1,748^{*}$ & $-1,769^{*}$ & 333.8 & $-1,853^{*}$ & $-1,882^{*}$ & 351.9 \\
\hline DifG210ShareP_? & - & - & - & - & - & - & $115273 \dagger$ & $117616 \dagger$ & $117105 \dagger$ & - & - & - \\
\hline DifG310ShareP_? & - & - & - & - & - & - & - & - & & $104,855 \dagger$ & $107,286 \dagger$ & $106,529 \dagger$ \\
\hline DifGini210Adj(-1) & $3,082 \dagger$ & $2,955^{* *}$ & $2,973 * *$ & $2,976^{* *}$ & $3,244^{* *}$ & $2,973 * *$ & $3,686 \dagger$ & $3,545 \dagger$ & $3,764 * *$ & - & - & - \\
\hline DifIdeal310(-1) & - & - & - & - & - & - & - & - & - & $879 \dagger$ & $828.2 \dagger$ & $889.8^{* * *}$ \\
\hline FE - Club & $*$ & $*$ & $*$ & $*$ & - & $*$ & $*$ & $*$ & - & $*$ & $*$ & - \\
\hline$\underline{\text { RE - Year }}$ & - & - & - & - & $*$ & - & - & - & $*$ & - & - & $*$ \\
\hline $\operatorname{adj} . R^{2}=$ & $=0.008$ & 0.007 & 0.007 & 0.007 & 0.010 & 0.021 & 0.111 & 0.112 & 0.113 & 0.112 & 0.113 & 0.114 \\
\hline $\mathrm{N}=$ & $=1955$ & 1955 & 1853 & 1853 & 1955 & 1955 & 1955 & 1853 & 1955 & 1955 & 1853 & 1955 \\
\hline Cross-Sections $=$ & 58 & 58 & 57 & 57 & 58 & 58 & 58 & 57 & 58 & 58 & 57 & 58 \\
\hline Years $=$ & $=107$ & 107 & 101 & 101 & 107 & 107 & 107 & 101 & 107 & 107 & 101 & 107 \\
\hline
\end{tabular}

$\dagger=$ significant at the $1 \%$ level, $* *=$ significant at the $5 \%$ level, $*=$ significant at the $10 \%$ level

In all specifications the competitive balance variable was positive and significant as were the measures of team performance. Attendance increases with decreases in competitive balance and increases with club performance gains. The more games played by each team the smaller the change in attendance per game. This may be a result of a fixed fan base with no change in income spreading their leisure dollar over more possible games resulting in lower attendance at each game. Inclusion of this variable is associated with a large increase in adjusted $\mathrm{R}^{2}$. Both the Interwar and Post2NoPre periods were generally negative and significant. Of the macroeconomic control variables used, RecssionLongMean showed consistently strong significance and was negative. The weak significance of other macroeconomic variables led to the use of RecessionLongMean in the initial, non-pooled regressions.

The interruptions in play and time path attendance suggest that changes may have occurred in how fans respond to competitive balance. The data was broken into three periods: PreWWOne, Interwar and Post WWII. Using the pooled data approach we ran regressions as before. Table 6 shows these results.

Table 6. DifAttTeamGm

\begin{tabular}{|c|c|c|c|c|c|c|c|c|c|c|c|c|}
\hline \multirow[b]{2}{*}{ Variable } & \multicolumn{3}{|c|}{ Pre WW-I } & \multicolumn{3}{|c|}{ Interwar } & \multicolumn{3}{|c|}{ Post2NoPre } & \multicolumn{3}{|c|}{ PostWWTwo } \\
\hline & Model 1 & Model 2 & Model 3 & Model 1 & Model 2 & Model 3 & Model 1 & Model 2 & Model 3 & Model 1 & Model 2 & Model 3 \\
\hline $\mathrm{C}$ & $-183,119 * *$ & $-199,951 \dagger$ & 1438 & $-258,032 \dagger$ & $-255,220 \dagger$ & 1.591 & 3,424 & 4,303 & $14,437 \dagger$ & 15,986 & 8,549 & 10,827 \\
\hline Year & $99.34 * *$ & $108.4 \dagger$ & - & $133.7 \dagger$ & $131.8 \dagger$ & - & 5.178 & 4.507 & - & -2.87 & 1.08 & - \\
\hline RecessLongMean & $-549.1^{*}$ & - & -655 & $-2,059 \dagger$ & - & $-2,051^{* *}$ & 406.5 & - & -158 & -89.86 & - & -141.46 \\
\hline GRGDPLongMean & - & $12,318.3^{*}$ & - & & $21,438 \dagger$ & - & - & $-169.2 * *$ & - & - & 6.72 & - \\
\hline Played_? & $-155.7 * *$ & $-176.8 \dagger$ & -26.33 & - & - & - & $-346.2 \dagger$ & $-325.2 \dagger$ & $-356.1 \dagger$ & -267.7 & -276.3 & -279.3 \\
\hline Premiership & - & - & - & - & - & - & - & - & - & 724.3 & 741.1 & 566.5 \\
\hline DifG210ShareP_? & $61,965 \dagger$ & $61,887 \dagger$ & - & $122,088 \dagger$ & $122,571 \dagger$ & - & $179,020 \dagger$ & $179,531 \dagger$ & - & $147,864 \dagger$ & $153,404 \dagger$ & - \\
\hline DifG310ShareP_? & - & - & $58,076 \dagger$ & & - & $116,592 \dagger$ & - & - & $164,496 \dagger$ & - & - & $136,490 \dagger$ \\
\hline DifGini210Adj(-1) & 1,857 & 1,677 & - & $7,813 \dagger$ & $6,409 \dagger$ & - & $5,573^{* *}$ & $5,358^{* *}$ & - & $4,047^{* * *}$ & $3,983^{*}$ & - \\
\hline DifIdeal310(-1) & - & - & 787 & - & - & $2,279 \dagger$ & - & - & 1,097 & - & - & 774.2 \\
\hline FE - Club & * & * & - & * & * & - & * & * & - & * & * & - \\
\hline RE - Year & - & - & $*$ & - & - & $*$ & - & - & $*$ & - & - & $*$ \\
\hline adj. $R^{2}=$ & 0.219 & 0.138 & 0.167 & 0.170 & 0.149 & 0.149 & 0.125 & 0.122 & 0.169 & 0.102 & 0.104 & 0.120 \\
\hline $\mathrm{N}=$ & 382 & 382 & 382 & 340 & 340 & 340 & 835 & 835 & 835 & 1233 & 1148 & 1233 \\
\hline Cross-Sections = & 32 & 32 & 32 & 36 & 36 & 36 & 47 & 47 & 47 & 52 & 52 & 52 \\
\hline Years $=$ & 24 & 24 & 24 & 17 & 17 & 17 & 43 & 43 & 43 & 66 & 61 & 66 \\
\hline
\end{tabular}

Pre-World War I the competitive balance variable is not significant though team performance and macroeconomic variables are significant and of the same sign as for the whole data set. For all later periods competitive balance measures are positive and significant. Recessions are negative and significant through the Interwar period, but insignificant after World War II. Team performance is positive and significant in all periods.

\section{Conclusion}

This paper examines the relationship between competitive balance and attendance in England's top level league since 1888. This was done both with league season total attendance and using a pooled approach with team game attendance as the dependent variable.

Our first step was developing an appropriate measure of competitive balance. There are competing measures of competitive balance in sports leagues. We used three of these measures and two point allocation approaches, resulting in six different measures of competitive balance. All six are highly correlated. In the regressions, sign and significance 
were the same for all measures. This indicates that the competing measures are capturing the same phenomenon.

English football has had four distinct eras in the period under examination: Pre-World War I, Interwar and Post World War II, which has two eras, the second beginning in 1992 with the Premiership's creation. Contrary to United States professional sports we find that increasing competitive balance in the English football is associated with decreases in attendance. This result is consistent across the most of the eras examined; the exception is the Pre-World War I era which showed no relationship between competitive balance and changes in attendance.

One of the difficulties with this paper is our inability to access stadia capacity. Attendance at games may, in many cases run into an upper bound so that increased attendance is not possible. We were using average attendance each year so that an increase, however, slight might still occur, unless all games in a season are sold out. A second, associated problem is that capacities might change year over year. Using the pooled data, fixed effects model with a time trend should mitigate some of this problem.

Improved club performance is a significant predictor of increases in attendance. Unsurprisingly, fans like their team winning and more makes them merrier. This result should be considered in light of the research on uncertainty of outcome that suggests that close matches are more attractive to fans. This latter is not directly tested, but the results indicate that perhaps English football fans are a different breed.

Combining the competitive balance results with those for club performance, it appears that English football fans prefer less competition while their team wins. This may demonstrate a preference for an exhibition of highly skilled talent. The much discussed strong loyalties of English football fans may well hold, but they appear to respond to club performance and league competitiveness.

These results stand in stark contrast to both the perceived wisdom of professional leagues in the United States and the empirical results from United States. Evidence from the United States clearly indicates that increasing competitive balance is associated with higher attendance. Consequently, leagues implement strategies, such as revenue sharing, that provide opportunity for lower revenue teams to maintain some semblance of high quality teams. The Premiership has following US leagues, implemented the same approach. In the case of the Premiership the evidence presented here suggests the Premiership policy of revenue sharing may be counter productive.

English football fans also appear to respond to income changes in a predictable fashion. During recessionary seasons attendance declines, indicating football matches are a normal good. Further, the more games in a season the lower the attendance growth. This suggests that football match attendance is fairly typical as a leisure good. More games played per season implies each fan attends the same number of games, though the fan base is spread over more games.

Examining the statistical results of different eras supports the visuals of Figure 1. During the Interwar period, attendance declined. In this period England was attempting to recover from WWI which may mean that leisure activities were generally less attractive. This downward trend persisted after WWII as well. The advent of the Premiership seems to have stopped the decline in attendance.

\section{References}

Berri, D. J., \& Schmidt, M. B. (2006). On the Road With the National Basketball Association's Superstar Externality. Journal of Sports Economics, 347-358. https://doi.org/10.1177/1527002505275094

Brandes, L., \& Franck, E. (2007). Who Made Who? An Empirical Analysis of Competitive Balance in European Soccer Leagues. Eastern Economic Journal, 33(3), 379-403. https://doi.org/10.1057/eej.2007.32

Cain, L. P., \& Haddock, D. D. (2006). Measuring Parity: Tying Into the Idealized Stadnard Deviation. Journal of Sports Economics, 7(3), 330-338. https://doi.org/10.1177/1527002504272937

Cavagnac, M. (2009). Revenue Sharing and Competitive Balance When Teams are not Wage Takers. Review of Industrial Organization, 35, 299-313. https://doi.org/10.1007/s11151-009-9230-3

Dobson, S., \& Goddard, J. (2004). Revenue Divergence and Competitive Balance in Divisional Sports League. Scotish Journal of Political Economy, 51(3), 359-376. https://doi.org/10.1111/j.0036-9292.2004.00310.x

Grossmann, M., Dietl, H., \& Lang, M. (2010). Revenue Sharing and Competitive Balance in a Dynamic Contest Model. Review of Industrial Orangizatin, 36, 17-36. https://doi.org/10.1007/s11151-009-9236-x

Hall, S., Szymanski, S., \& Zimbalist, A. S. (2002). Testing Causality Between Team Performance and Payroll: The Cases of Major League Baseball and English Soccer. Journal of Sports Economics, 3(2), 149-168. https://doi.org/10.1177/152700250200300204

Hausman, J. A., \& Leonard, G. K. (1997). Superstars in the National Basketball Association; Economic Value and Policy. Journal of Labor Economics, 15(4), 586-624. https://doi.org/10.1086/209839 
Hogan, V., Massey, P., \& Massey, S. (2013). Competitive Balance and Match Attendance in European Rugby Union Leagues. The Economic and Social Review, 44(4), 425-446.

Jennett, N. I. (1984). Attendances, Uncertainty of Outcome and Policy in Scottish League Football. Scottish Journal of Political Economy, 31(2), 176-198. https://doi.org/10.1111/j.1467-9485.1984.tb00472.x

Jewell, R. T., Simmons, R., \& Szymanski, S. (2014). Bad for Business? The Effects of Hooliganism on English Professional Football Clubs. Journal of Sports Economics, 15(5), 429-450. https://doi.org/10.1177/1527002514535169

Kesenne, S. (2006). Competitive Balance in Team Sports and the Impact of Revenue Sharing. ournal of Sport Management, 20, 39-51.

Knowles, G., Sherony, K., \& Haupert, M. (1992). The Demand for Major League Baseball: A Test of the Uncertainty of Outcome Hypothesis. The American Economist, 36(2), 72-80. https://doi.org/10.1177/056943459203600210

Lambert, P. (1993). The Distribution and Redistribution of Income. s.1.:Manchester University Press.

Lee, H. Y., \& Fort, R. (2012). Competitive Balance: Time Series Lessons from the English Premier League. Scottish Journal of Political Economy, 59(3), 266-282. https://doi.org/10.1111/j.1467-9485.2012.00580.x

Lee, Y. H., \& Fort, R. (2005). Structural Change in MLB Competitive Balance: The Dpression, Team Location and Integration. Economic Inquiry, 43(1), 158-169. https://doi.org/10.1093/ei/cbi011

Mizak, D., Stair, A., \& Rossi, A. (2005). Assessing Alternative Competitive Balance Measures for Sports Leagues: A Theoretical examination of Standard Deviations, Gini Coefficients, the Index of Dissimilarity. Economics Bulliten, 12(5), 1-7.

Neale, W. C. (1964). The Peculiar Economics of Professional Sports. The Quarterly Journal of Economics, 1-14. https://doi.org/10.2307/1880543

Owen, P. D., Ryan, M., \& Weatherston, C. R. (2007). Measuring Competitive Balance in Professional Team Sports Using the Herfindahl-Hirschman Index. Review of Industrial Organization, 31, 289-302. https://doi.org/10.1007/s11151-008-9157-0

Palomino, F., \& Tigotti, L. (2000). The Sport League's Dilemma: Competitive Balance Versus Incentives to Win, s.1.: Tilburg University CentER for Economic Research Working Paper No. 2000-109.

Paul, R. J., \& Weinbach, A. P. (2007). The Uncertainty of Outcome and Scoring Effects on Nielsen Ratings for Monday Night Football. Journal of Economics and Business, 59(3), 199-211. https://doi.org/10.1016/j.jeconbus.2006.05.001

Peel, D., \& Thomas, D. (1988). Outcome Uncertainty and the Demand for Football: An Analysis of Match Attendance in the English Footbal League. Scottish Journal of Political Economy, 242-249. https://doi.org/10.1111/j.1467-9485.1988.tb01049.x

Peel, D., \& Thomas, D. (1992). The Demand for Football: Some Evidnece on Outcome Uncertainty. Scottish Journal of Political Economy, 17(2), 323-331. https://doi.org/10.1007/bf01206291

Peeters, T. (2015). Profit-Maximizing Gate Revenue Sharing in Sports Leagues. Economic Inquiry, 53(2), 1275-1291. https://doi.org/10.1111/ecin.12184

Rascher, D. (1999). A Test of the Optimal Positive Production Network Externality in Major League Baseball, s.1.: MPRA.

Rascher, D. A., \& and Solmes, J. P. G. (2007). Do Fans Want Close Contests? A Test of the Uncertainty of Outcome Hypothesis in the National Basketball Association. Kinesiology (Formerly Exercise and Sport Science), 130-141. https://doi.org/10.2139/ssrn.1690886

Runkel, M. (2011). Revenue Sharing, Competitive Balance and the Contest Success Function. German Economic Review, 12(3), 256-273. https://doi.org/10.1111/j.1468-0475.2011.00530.x

Scelles, N. et al., (2013). Competitive Balance Versus Competitive Intensity Before a Match: Is One of These Two concepts More Relevant in Explaining Attendance? The Case of the French Football Ligue 1 Over the period 2008-2011. Applied Economics, 45(29), 4184-4192. https://doi.org/10.1080/00036846.2013.770124

Schmidt, M. B., \& Berri, D. J. (2001). Competitive Balance and Attendance: The Case of Major League Baseball. Journal of Sports Economics, May, 2(2), 145-167.

Siegfried, A. R., \& Sanderson, J. J. (2003). Thinking About Competitive Balance. Journal of Sports Economics, 1-25. 
Surdam, D. G. (2009). What Brings Fans to the Ball Park? Evidence from New York Yankees' and Philadelphia Phillies' Fiancial Records. The Journal of Economics, 35(1), 35-47.

Szymanski, S. (2001). Income Inequality, Competitive Balance and the Attractiveness of Team Sports: Some Evidence and a Natural Experiment from English Soccer. The Economic Journal, 111(469), F69-F84. https://doi.org/10.1111/1468-0297.00599

Szymanski, S., \& Kesenne, S. (2004). Competitive Balance and Gater Revenue Sharing in Team Sports. The Journal of Industrial Economics, 52(1), 165-177. https://doi.org/10.1111/j.0022-1821.2004.00220.x

Tainsky, S., \& Winfree, J. A. (2010). Short-Run Demand and Uncertainty of Outcome in Major League Baseball. Review of Industrial Organization, 37, 197-214. https://doi.org/10.1007/s11151-010-9267-3

Utt, J., \& Fort, R. (2002). Ptifalls to Measuring Competitive Balance with Gini Coefficients. Journal of Sports Economics, 3(4), 367-373. https://doi.org/10.1177/152700250200300406

Vrooman, J. (2009). Theory of the Perect Game: Competitive Balance in Monopoly Sports Leagues. Review of Industrial Organization, 34, 5-44. https://doi.org/10.1007/s11151-009-9202-7

\section{Copyrights}

Copyright for this article is retained by the author(s), with first publication rights granted to the journal.

This is an open-access article distributed under the terms and conditions of the Creative Commons Attribution license which permits unrestricted use, distribution, and reproduction in any medium, provided the original work is properly cited. 